\title{
Empreendedorismo no Brasil, inovação e startups
}

\author{
Entrepreneurship in Brazil, innovation and startups \\ Emprendimiento en Brasil, innovación y startups
}

Recebido: 04/03/2021 | Revisado: 11/03/2021 | Aceito: 15/05/2021 | Publicado: 01/06/2021

\author{
Torben Fernandes Maia \\ ORCID: https://orcid.org/0000-0003-3053-3062 \\ Universidade de São Paulo, Brasil \\ E-mail: torben@paulomaia.adv.br \\ Paulo Antônio Maia e Silva Junior \\ ORCID: https://orcid.org/0000-0003-0846-0952 \\ Universidade Federal da Paraíba, Brasil \\ E-mail: paulojr@paulomaia.adv.br \\ José Cândido da Silva Nóbrega \\ ORCID: https://orcid.org/0000-0002-0976-3763 \\ Universidade Federal de Campina Grande, Brasil \\ E-mail: jcandidosn@uol.com.br \\ Francisco das Chagas Bezerra Neto \\ ORCID: https://orcid.org/0000-0001-6232-4383 \\ Universidade Federal de Campina Grande, Brasil \\ E-mail: chagasneto237@gmail.com
}

\begin{abstract}
Resumo
O presente estudo vislumbra analisar alguns apontamentos acerca do empreendedorismo e as startups, sobretudo no que tange o crescimento econômico e a solução das problemáticas comuns. Nessa perspectiva, este artigo, através da pesquisa exploratória, de natureza qualitativa, método dedutivo, coleta de dados documental e bibliográfica, procedeuse de modo a realizar uma análise minuciosa do arcabouço normativo que trata acerca das startups. Não obstante, elucidou também sobre a inexiste de qualquer diferenciação ou privilégios concedidos a essa espécie empresarial, aplicando-se a ela todos os ditames legais das mais diversas searas jurídicas, desde a trabalhista, tributária, cível, penal e empresarial. Dessa maneira, diante da problemática exposta, buscou-se, elucidar a necessidade do Estado, pautado na segurança jurídica e no crescimento econômico, implantar tratamento específico para as startups, tendo em vista que estas possuem grande potencial de contribuição para o nosso país, seja porque vão gerar renda, empregos, arrecadação para o Estado, movimentação da economia, entre outros.
\end{abstract}

Palavras-chave: Startups; Segurança jurídica; Crescimento econômico.

\begin{abstract}
This study aims to analyze some notes about entrepreneurship and startups, especially with regard to economic growth and the solution of common problems. In this perspective, this article, through exploratory research, of a qualitative nature, deductive method, collection of documentary and bibliographic data, proceeded in order to carry out a detailed analysis of the normative framework it deals with about startups. Nevertheless, it also clarified the lack of any differentiation or privileges granted to this business species, applying to it all the legal dictates of the most diverse legal fields, from labor, tax, civil, criminal and business. Thus, in view of the exposed problem, it was sought to elucidate the need of the State, based on legal security and economic growth, to implement specific treatment for startups, considering that they have great potential for contributing to our country, be it because they will generate income, jobs, revenue for the State, movement of the economy, among others.
\end{abstract}

Keywords: Beginners; Legal certainty; Economic growth.

\section{Resumen}

Este estudio tiene como objetivo analizar algunas notas sobre emprendimiento y startups, especialmente en lo que respecta al crecimiento económico y la solución de problemas comunes. En esta perspectiva, se procedió a este artículo, a través de una investigación exploratoria, de carácter cualitativo, método deductivo, recolección de datos documentales y bibliográficos, con el fin de realizar un análisis detallado del marco normativo que trata sobre las startups. Sin embargo, también aclaró la falta de cualquier diferenciación o privilegios otorgados a esta especie empresarial, aplicándole todos los dictados legales de los más diversos ámbitos jurídicos, desde el laboral, tributario, civil, penal y empresarial. Así, ante la problemática expuesta, se buscó dilucidar la necesidad del Estado, basado en la seguridad jurídica y el crecimiento económico, de implementar un tratamiento específico para las startups, considerando que tienen un gran potencial para contribuir a nuestro país, ya sea porque generarán ingresos, empleos, ingresos para el Estado, movimiento de la economía, entre otros.

Palabras clave: Principiantes; Seguridad jurídica; Crecimiento economico. 


\section{Introdução}

Preliminarmente, é preciso definir o que se entende por empreendedorismo. Foi adotado o conceito de empreender como sendo uma atividade pela qual se realizam ações e materializam-se novas ideias, buscando desenvolver e dinamizar serviços, produtos ou qualquer outra atividade de administrar e organizar atividades empresariais (Empreendedorismo, 2018). Durante muito tempo, o empreendedorismo tradicional foi o motor responsável pelo desenvolvimento da economia, geração de empregos e movimentação da renda na maior parte da história da economia mundial. Essa forma de empresariar, considerada convencional, pode ser compreendida como aquela atividade comercial comum, pautada pela reprodução de um modelo de negócio já conhecido e consolidado no mercado, do qual não demanda grande inovação e muitas vezes não busca a solução de um problema.

É baseado em uma estrutura de mercado burocrática e caríssima, que é repleta de meandros que dificultam a entrada de novos atores desprovidos de capital financeiro próprio considerável e experiência no setor. Também é marca comum a ausência de colaboração, em detrimento de uma concorrência agressiva.

Todavia, nos dois últimos séculos, a humanidade presenciou fatos históricos que trouxeram grandes impactos econômicos e sociais para todo o planeta. Aconteceram duas grandes guerras mundiais, quatro revoluções industriais (Schwab, 2018), e tudo isso afetou diretamente o cotidiano das pessoas.

O mundo entrou num processo de globalização, onde as fronteiras, que eram até então bem delimitadas, começaram a ser desmistificadas. Os mercados que eram nacionais, passaram a assumir uma vocação mundial e o intercâmbio de ideias passou a correr livre. Um produto inventado nos Estados Unidos, é produzido na China e consumido no mundo todo.

Maurício Benvenutti fala que "não existem mais 200 países. Formamos hoje um único mercado. Qualquer pessoa, em qualquer lugar e a qualquer momento, pode criar algo e impactar milhões ou bilhões de indivíduos” (Benvenutti, 2018, p. 21).

Aliado a isso, a internet surgiu e se popularizou, bem como tecnologias, que fizeram com que condições que até então eram de exclusividade de grandes corporações, governos ou pessoas muito ricas (Benvenutti, 2018) se tornassem mais acessíveis a qualquer pessoa e em qualquer local do planeta. Prova disso é o fato de que uma pessoa que possuir um smartphone no Quênia já acessa mais informações do que Bill Clinton quando foi presidente dos Estados Unidos em 1990 (Diamandis, 2016).

Foi através do surgimento e desenvolvimento da internet que as startups encontraram o elemento propulsor para o seu nascimento e crescimento exponencial. É que "a internet havia chegado para quebrar o paradigma da velha economia" (Azevedo, 2016, p. 13), uma vez que esse novo dispositivo foi responsável por reconfigurar completamente o status quo estabelecido até então no mundo dos negócios.

Tendo em vista a relevância do tema proposto, será realizada uma pesquisa exploratória, que tem por objetivo proporcionar uma maior familiaridade com o problema. Sem a perspectiva de esgotamento do tema, tratar-se-á, sobretudo, acerca do empreendedorismo no Brasil. Ademais, se utilizará do método de abordagem dedutivo, uma vez que se buscará os resultados a partir da análise geral até concluir de maneira particular a hipótese. Quanto à natureza da pesquisa, esta será qualitativa, buscarse-á analisar e interpretar os institutos do Direito Empresarial, como forma de chegar à conclusão que as startups são de extrema relevância para o crescimento econômico internacional e nacional.

Quanto ao método de procedimento, atribuir-se-á o método monográfico, partindo de um estudo profundo sobre as startups, que podendo esta pesquisa ser considerada representativa de muitos outros ou mesmo de todos os casos semelhantes. Além do mais, quanto aos procedimentos técnicos, se delineará o presente estudo por meio de pesquisa bibliográfica e documental, tendo em vista que se buscará, através da renomada doutrina do direito e periódicos especializados, bem como através da interpretação das leis, a solução para impulsionar o desenvolvimento econômico.

No presente trabalho, portanto, serão apresentados alguns apontamentos acerca do empreendedorismo e as startups. Não obstante, será abordado o arcabouço normativo destas. Nesse contexto, vale salientar a extrema importância das startups para o crescimento econômico e a solução das problemáticas comuns. 


\section{Desenvolvimento}

Em 1993 com a criação do Mosaic, navegador que popularizou e transformou a web no modelo que conhecemos hoje: foi dado o pontapé inicial para o surgimento e explosão das empresas "pontocom", aquelas que são baseadas na internet, pois realizam suas vendas, divulgação de seus produtos e serviços, fazem o seu marketing e outra funções todas majoritariamente no ambiente virtual. Dentre elas, podemos citar a Amazon e o Yahoo, startups que foram fundadas nesse período e se consolidaram no mercado, permanecendo até os dias atuais como corporações gigantescas, cujo valor de mercado ultrapassa vários bilhões de dólares.

Foi, sobretudo, pelo sucesso estratosférico de jovens universitários, carentes de estrutura física e de capital inicial, que pautados por tecnologia e imbuídos pelo desenvolvimento de novos produtos e serviços, criaram multinacionais gigantescas que surgiram em seus dormitórios, chamando a atenção de todo o mundo.

Como exemplo, Mark Zuckberg, um dos fundadores da rede social Facebook - maior empresa de mídias do mundo, mas que não produz nenhum conteúdo, com valuation (valor de mercado) superior a US\$ 500 bilhões. Nathan Blecharczyk, Brian Chesky e Joe Gebbia, fundadores da Airbnb, maior rede de hotéis do mundo, mas que não possui um único leito sequer. Travis Kalanick e Garrett Camp, fundadores da Uber, maior empresa de transporte de passageiros do mundo, e que não possui nenhum automóvel.

Dessa forma, aquele empreendedorismo tradicional começa a dar sinais de esgotamento, e passa a ser substituído pelo modelo presente no ecossistema das startups. Diferente de outras empresas, estas surgem a partir de um problema que é comum e recorrente a várias pessoas, e o seu produto ou serviço é a solução inteligente para esses problemas.

Onde há problemas e desencontros, existe oportunidade de negócio, e é aí que as startups encontram o espaço para surgir e se desenvolver. Iniciar uma empresa nesse ambiente é simples e custa bem menos, em função de o leque de investimentos estar mais disponível e o acesso à propriedade tornar os meios de produção mais democráticos.

Visando facilitar o que está sendo explicado, foi elaborada a seguinte Figura que ilustra de maneira bastante didática como acontece o processo de surgimento dessas empresas:

Figura 1 - Esquema de surgimento de ideia de startup

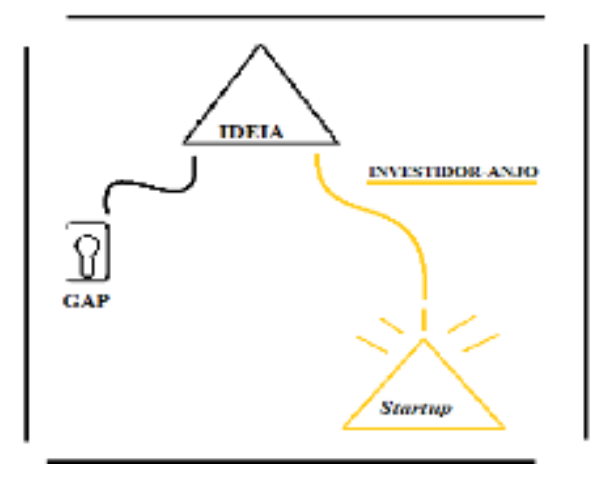

Fonte: Autoria própria (2021).

GAP é um termo inglês que faz menção à lacuna, vão ou espaço vazio. Trazendo para o caso discutido um "gap"; portanto, seria uma oportunidade vista pelo empreendedor de montar um negócio que irá oferecer uma solução para determinado problema. Assim, muitas vezes o fundador da startup tem apenas a ideia, não dispondo de capital algum.

Isso porque está mais barato e fácil abrir um negócio. Na década de 1990, uma linha telefônica custava \$5 mil dólares (Estadão, 2018). O Google disponível hoje para uma pessoa no interior da Paraíba é o mesmo acessado por Larry Page, fundador 
dessa empresa. Coworks ${ }^{l}$, que são espaços compartilhados de escritórios, com toda estrutura física e pessoal já incluídos a custos baixíssimos, já são realidade em todo o país.

Isso se dá, também, pelo fato de que atualmente não é mais preciso ser proprietário de bens e usuário de serviços caríssimos. Trata-se de fenômeno disruptivo que começa a reformular o direito civil mundial. É que os cidadãos estão optando por acessar e utilizar, em detrimento do ter e possuir.

É exatamente o que empresas como a Netflix, Coworking, Uber, Spotify proporcionam aos seus usuários. Ao invés de adquirir e manter uma infinidade de CDs de músicas, quando se pode acessar as faixas de qualquer artista virtualmente, por que alugar ou adquirir CDs e DVDs de filme, quando é possível acessá-los facilmente e a baixíssimo custo na internet?

Todas essas plataformas disruptivas de serviços iniciaram um ciclo que Peter Diamandis nomeou como 6D (Diamandis, 2016). Primeiro, houve a digitalização das coisas: do papel para o Word, do CD para o MP3, da foto impressa para o celular. Posteriormente, veio a decepção: no início, o acesso aos arquivos digitalizados foi terrível, em função da fraca estrutura e velocidade lenta da internet, as primeiras experiências foram ruins.

Porém, com o avanço da tecnologia, veio a disrupção e substituição dos meios até então tradicionais e consolidados, por ferramentas novas, reformulando o mercado tradicional e mudando as regras do jogo. Foi assim que foi aberto espaço para a desmaterialização dos produtos e serviços: calculadoras, agendas, scanners, rádios, despertadores, tudo se transformou em aplicativos de celulares. Lojas físicas deram lugar ao e-commerce, agências bancárias viraram dispositivos virtuais (Benvenutti, 2018).

Todo esse processo tornou o acesso a essas tecnologias mais baratas. Dispor de milhares de músicas, filmes e informações custa dezenas de reais. Ligações internacionais, videoconferências, mensagens instantâneas passaram a ser gratuitas, puxando um fenômeno de desmonetização de produtos e serviços. Um smartphone hoje aglomera um grupo de serviços que em 1980 custavam mais de 1 milhão de dólares (Ramirez, 2016).

Com a desmonetização e desmaterialização, o acesso se torna mais democrático, pois é permitido a mais pessoas consumirem essas tecnologias que estavam à disposição apenas às classes mais privilegiadas, governos ou grandes corporações.

Everilda Brandão Guilhermino, quando escreveu sobre a tutela das multititularidades, consignou que "na era contemporânea, as riquezas perdem a sua densidade, chegando-se a falar em despatrimonialização dos bens" (Guilhermino, 2018, p. 9). Bauman precisamente nomeou esse novo panorama como modernidade leve ou líquida (Bauman, 2014), um universo novo onde os bens e coisas são incorpóreos, provocando impactos profundos sobre as relações sociais, o que Guilhermino atenta para a reformulação sobre o direito ao pertencimento e da apropriação de bens.

Todo esse panorama já atrai muita atenção do mercado, fazendo com que investidores tenham seus olhos voltados e fixados nesse ecossistema, tornando o acesso a investimentos, até mesmo em quantias vultuosas, mais próximo, sendo uma alternativa mais interessante do que o crédito oferecido por instituições bancárias.

Prova disso é que no ano de 2017, apenas a classe de investidores-anjos investiu quase $\mathrm{R} \$ 1$ bilhão de reais no Brasil (Dagnino, 2017). Essa é uma nova realidade empreendedora mundial, e que começa a se reproduzir também aqui no nosso país, e isto tem facilitado bastante a vida de pessoas que têm interesse em empreender, uma vez que diversas ferramentas foram criadas e conseguem baratear o custo, o que faz com que exista um incentivo à iniciativa e manutenção de uma cultura empreendedora.

${ }^{1}$ Cowork é um termo inglês, cuja tradução significa compartilhamento do trabalho. É um modelo de trabalhar baseado no compartilhamento de espaço e recursos disponíveis em determinado espaço entre profissionais que podem não ser da mesma empresa ou sequer do mesmo ramo de atuação. Assim, como mais de uma pessoa de empresas distintas ocupam o mesmo espaço, os custos que no modelo tradicional seriam arcados por um único consumidor, passam a ser rateados entre todos, diminuindo consideravelmente as despesas individuais necessárias para a manutenção. 
Há que se atentar, todavia, para a divisão de riscos e benefícios dessa relação entre investidor e investido para que ela não ocorra de maneira desproporcional. Deve-se afastar a ingenuidade para perceber que essa facilidade de acesso ao capital muitas vezes cobra juros elevados e distribui de maneira desigual os ônus da responsabilidade entre esses dois players.

Muito embora o fundador da empresa entre apenas com a ideia e a sua força de trabalho nesse projeto, cabendo ao investidor aportar os recursos financeiros necessários para tirar a ideia do papel e ser o pontapé inicial, os riscos de eventual falência da empresa não podem ser depositados com exclusividade na conta do idealizador apenas, que, muitas vezes, do ponto de vista financeiro, é o ator que dispõe de lastro financeiro mais sensível para suportar eventuais responsabilidades decorrentes da bancarrota.

Assim, essa é uma dificuldade enfrentada pelo legislador quando se propõe a regular esse cenário. Isso porque essa nova realidade de oferta de crédito ocorre, sobretudo, porque está sendo muito lucrativo investir em startups, e não porque o capitalismo se tornou filantrópico. O eventual retorno financeiro de um investimento em uma startup que deu certo e que se tornou escalável, é absurdo e muitas vezes inalcançável em outras modalidades de investimento.

Isso fez com que o mercado de investidores passasse a voltar olhares atenciosos para esse nicho empresarial, uma vez que uma de suas características é o crescimento exponencial, em função da sua escalabilidade, tornando as margens de lucros altíssimas.

Voltando ao surgimento de uma startup, um bom exemplo de GAP visto e explorado foi o encontrado pelo WhatsApp: uma empresa que até 2014 tinha em seus quadros apenas 55 funcionários (Forbes, 2014), mas que, ainda assim, venceu uma disputa de um mercado bilionário com gigantes do setor de telecomunicações que lutavam por preços competitivos em ligações telefônicas para fora dos países.

Essa firma tornou esse serviço, que até então era caríssimo e problemático, e, portanto, de acesso exclusivo a pouquíssimas pessoas de elevado poder aquisitivo, gratuito e disponível a qualquer pessoa em qualquer local do mundo, reformulando completamente o setor e sem deixar saudades dos antigos fornecedores. Foi assim que em 2014 ela foi vendida para o Facebook por $\$ 18$ bilhões de dólares.

Robin Chase, cofundadora da Zipcar, empresa norte-americana de compartilhamento de carros, fez interessante análise pela atual transformação social que se atravessa. Ela chamou de nova economia colaborativa a nova estrutura econômica que começa a substituir a indústria tradicional. A autora chama atenção para um fato interessante, que embora ela aponte como sendo característica de um cenário macroeconômico inovador que começa a se instalar generalizadamente, é uma qualidade muito nítida, e, até então, peculiar desse ecossistema de startups: a colaboração.

Trata-se de um dever observado satisfatoriamente por todos os players inseridos nesse ambiente. E esse é mais um elemento propulsor responsável por fazer as coisas acontecerem, proporcionar crescimento e desenvolvimento das empresas inseridas nessa realidade. Enquanto a "economia industrial concentra poder e riqueza, a economia colaborativa os distribui." (Chase, 2015, p. 292).

Trata-se de verdadeira quebra de paradigma, onde havia até então um modelo de economia capitalista que vigorou imperiosamente durante séculos. Proprietários em pé de guerra com trabalhadores, produtores contra consumidores, onde a prosperidade era exclusividade dos possuidores dos meios de produção, que também detinham a propriedade intelectual, segredos comerciais, direitos autorais, equipamentos e funcionários (Chase, 2015, p. 290).

Romper com esse status quo era atividade hercúlea exercida isoladamente. Isso porque o excesso de regulação e as estruturas estabilizadas foram posicionadas para dificultar a entrada de novos players no mercado.

A colaboração é também uma característica marcante desse novo conceito de empreender, o qual é forte elemento que distingue o capitalismo industrial, marcado pelo individualismo, competitividade agressiva e asfixiadora de diversidade, onde o 
concorrente é visto como inimigo a ser destruído. Na economia colaborativa, Robin Chase elencou de maneira muito precisa os quatro princípios que são responsáveis por mover essa nova sistemática:

\section{Ativos abertos acessíveis > ativos fechados}

Os ativos abertos proporcionam mais valor do que os ativos fechados por serem utilizados com mais eficiência e por nos permitirem descobrir continuamente novas e valiosas utilizações.

2. Mais mentes em rede> menos mentes muradas

Um número maior de pessoas é mais inteligente que um menor de pessoas, mas só quando elas estão conectadas na rede.

3. Benefícios da abertura > problemas da abertura

Coletivamente, as oportunidades vantajosas da inovação e da aprendizagem compartilhada são muito maiores do que os problemas desvantajosos, como mau comportamento, que podem ser identificados e resolvidos com sistemas de avaliações, comentários e redes de confiança.

4. Eu recebo > eu dou

Individualmente, cada pessoa que contribui com ativos a uma plataforma necessariamente recebe mais do que dá. É assim que funcionam a Wikipédia, as refeições comunitárias e os impostos que pagam por bibliotecas públicas e pela defesa nacional. (Chase, 2015, p. 289).

Essas novas empresas, que são responsáveis pela atual mudança de paradigmas que se vivencia na sociedade e nas relações sociais, também produz consequências no mundo jurídico. Isso porque a modernidade tem como composição majoritária bens e coisas incorpóreos. A "propriedade que era sólida e feita para durar" (Guilhermino, 2018, p. 20) começa a ser descontruída, uma vez que elas não se limitam mais apenas à satisfação exclusiva dos seus proprietários.

Há uma opção da coletividade em não mais possuir, mas apenas acessar e usufruir do bem alheio, o qual inicialmente possuía até então um valor extremamente particular e individualizado, passa a desempenhar uma função que transcende essa esfera individualista, para um valor social. É o que Everilda Guilhermino chama de bem difuso, cuja essência está na apropriação compartilhada:

Estes proprietários buscam o seu legado, o qual transcende o que lhe pertence individualmente. Estes novos bens só são acessados e usufruídos por muitas pessoas além do seu titular (...). Agrega-se ao patrimônio individual um segundo valor, de modo que o primeiro realiza o proprietário, e o segundo realiza a sociedade (...), redimen sionando o sentido do "ter" exclusivo e consolidado nos ordenamentos da modernidade. (Guilhermino, 2018, p. 28).

A economia do compartilhamento, economia colaborativa, dentre outros, são diversos termos escolhidos por estudiosos do tema o qual reforça essa marca presente no ecossistema das startups, que aparenta ser característica presente desse novo modelo econômico de produção de riquezas que começa a se desenhar na economia global, onde empresas e negócios surgem a partir da colaboração e compartilhamento de dados, informações, bens e propriedades. Uma opção que propõe um novo estilo de vida que valoriza não mais o ter e possuir, mas sim o acessar e usufruir.

Conceituar startup é uma árdua missão, posto que se trata de temática atual e nova para o mundo jurídico, o que faz com que exista pouco material acadêmico sobre, de modo que inexiste ainda uma definição pacificada sobre um conceito fechado na doutrina que se debruça sobre essa temática.

Eric Ries (2012), americano estudioso sobre o tema, definiu startup como "uma instituição humana projetada para criar novos produtos e serviços sob condições de extrema incerteza". Há também uma importante definição feita por Steve Blank e Bob Dorf, que é importante citar, uma vez que complementa a concepção feita por Ries. Segundo Blak e Dorf, startups seriam organizações voltadas para encontrar um modelo de negócios que é lucrativo, repetível e escalável (Blank \& Dorf, 2012, p. 27).

Embora se trate de autores distintos, entende-se que a melhor forma para enxergar uma startup seria a complementação do conceito elaborado por ambos escritores, posto que o elemento comum a essas empresas é o fato de estarem inseridas num modelo de negócios completamente desconhecido e incerto, mas que tem grande potencial lucrativo, escalável e disruptivo. 
No senso comum, é costumeiro as pessoas enxergarem uma startup como sendo qualquer empresa que tenha um pequeno porte, que esteja no início de suas atividades e que se utilize de muita tecnologia em suas operações. Logo, é preciso desde já esclarecer que essa é uma visão equivocada sobre a caracterização de startups.

Isso porque não é apenas o momento de abertura, o tamanho ou a utilização de tecnologias a característica fundamental que irá definir uma companhia dessa forma. É preciso que o seu modelo de negócios esteja inserido num ambiente de grandes incertezas e riscos, porque não existe até o seu surgimento um exemplo a ser seguido, de modo que é a incerteza o elemento mais importante para definir a empresa como startup ou não.

Não é que empresas que atuam fora desse ramo são providas de certezas e garantias, uma vez que insegurança e instabilidade são elementos inerentes e inseparáveis para aqueles que atuam na iniciativa privada. Todavia, no mercado de startups esses componentes são apresentados de maneira mais acentuada, posto que se trata de propostas pioneiras e inovadoras, que geralmente encontram forte resistência dos consumidores. Não é à toa que 50\% das startups fecham as portas nos quatro primeiros anos de nascimento (Arruda et al., 2012).

Alguns países, ao enxergar o potencial desse novo ramo empresarial que começou a se desenvolver, pronunciaram-se legislativamente, conferindo segurança jurídica a partir de uma definição técnica/legal sobre os requisitos para uma empresa ser encarada como uma startup. Destaca-se a Itália, que através da Lei n 221/2012 considera startup qualquer empresa que tenha constituição de no máximo cinco anos, com sede nesse país, não distribua lucros aos seus sócios e possua um faturamento anual de cinco milhões de euros.

A França também editou normativo, definindo que é preciso que a empresa tenha constituição máxima de oito anos, qualificação como microempresa ou de pequeno porte e que no mínimo $50 \%$ das suas quotas ou ações de propriedade sejam compostas por empreendedores ou fundos de venture capital.

No Brasil, existe desde 2006 a lei complementar 123 que instituiu o Estatuto Nacional da Microempresa e Empresa de Pequeno Porte (ENMEP). No ano de 2016, o Congresso Nacional aprovou a Lei Complementar 155 que modificou esse estatuto, acrescentando diversos benefícios para o exercício dessas MPEs.

Porém, essa regulamentação foi silente no que se refere a uma definição sobre startups para o nosso país, pois ficou restrita ao investimento-anjo, que é uma modalidade de financiamento muito utilizada no ecossistema de startups, demonstrando certa sensibilidade do legislativo para essa nova realidade empreendedora que começa a ganhar espaço também por aqui, atitude que é louvável nesse ponto, mas criticável no que se refere à sua omissão.

Deve-se dar destaque ao Projeto de Lei n ${ }^{\circ} 321 / 2012$ já aprovado pelo Senado Federal, em tramitação na Câmara dos Deputados como PL n 6.625/2013, a qual seria a principal norma do nosso país sobre essa matéria. Isso porque esse texto legal visa criar um Sistema de Tratamento Especial a Novas Empresas de Tecnologia (SisTENET). Segundo parecer já aprovado, trata-se de projeto que concede "isenção de impostos federais para empresas de tecnologia nascentes (start-ups)" (Brasil, 2013).

Entretanto, a distinção deve ser feita para o art. $2^{\circ}$ dessa lei, a qual define "Start-up" como sendo uma "Nova Empresa de Tecnologia", limitando esse conceito às companhias que realizem, exclusivamente, atividades de informática e telemática, e que disponham de receita limitada a trinta mil reais por trimestre e com até quatro funcionários. O critério que limita a renda trimestral a $\mathrm{R} \$ 30.000,00$ (trinta mil reais) resulta numa receita anual de $\mathrm{R} \$ 120.000,000$ (cento e vinte mil reais), o que proporciona uma renda mensal de $\mathrm{R} \$ 10.000,00$ (dez mil reais), pelo prazo máximo de dois anos, prorrogáveis por igual período.

Esse dispositivo se trata de um parâmetro insuficiente, posto que quando se parte para a realidade, uma startup que continua com faturamento desse nível, é porque não deu certo, resultando num efeito prático normativo de baixíssima adesão de startups ao SISTENET.

Contudo, a pior restrição poderia ser feita pelo próprio conceito de startups, caso o projeto houvesse sido aprovado. É porque ele se limita apenas àquelas empresas que realizem atividades de informática ou telemática, o que aparenta ser uma visão 
míope sobre esse cenário empreendedor, haja vista que muitas startups possuem vocação para inúmeras outras atividades que não têm qualquer relação direta e imediata com os serviços de informática ou telemática, e que, portanto, estariam excluídas desse benefício.

Prova disso ficou registrada na nota técnica CETAD/COEST número 7 de 13 de janeiro de 2016, elaborada pela Receita Federal do Brasil, que atendendo a ofício encaminhado pela comissão de finanças e tributação da Câmara dos Deputados, na época em que o PL n ${ }^{\circ}$ 6.625/13 tramitou por lá, requisitou uma estimativa de impacto orçamentário-financeiro caso a proposta viesse a ser aprovada, em função do regime tributário diferenciado que ela poderia produzir.

No começo do ano de 2019, foi promulgada a Lei Complementar $n^{\circ} 167$, onde dentre outros pontos, alterou a Lei Complementar n ${ }^{\circ} 123$ que é a norma que institui o Estatuto Nacional da Microempresa e Empresa de Pequeno Porte, instituindo o Inova Simples. No meio dos demais dispositivos, aquele que mais interessa a essa dissertação, se trata que criou o Inova Simples.

Ficou criado um regime especial simplificado, o qual visa conceder às iniciativas empresariais que possuam caráter incremental ou disruptivo, que se autodeclararem como startup ou empresas de inovação, estabelecendo para elas um tratamento tributário diferenciado, visando estimular a criação, formalização, desenvolvimento e a consolidação dessas empresas como agentes que induzam o avanço tecnológico, gerem emprego e renda para a população.

Há que louvar a iniciativa dessa legislação, que vai de encontro a tudo que é discutido não apenas por este trabalho, mas por demais estudiosos dos mais variados segmentos científicos.

Art. 65-A. É criado o Inova Simples, regime especial simplificado que concede às iniciativas empresariais de caráter incremental ou disruptivo que se autodeclarem como startups ou empresas de inovação tratamento diferenciado com vistas a estimular sua criação, formalização, desenvolvimento e consolidação como agentes indutores de avanços tecnológicos e da geração de emprego e renda. (Brasil, 2019).

Em função de serem corporações que em sua maioria nasceram há bem pouco tempo, essas se formam inseridas dentro do cenário da quarta revolução industrial, pautadas por muita tecnologia em seu processo de produção, o que potencializa consideravelmente os resultados que possam ser alcançados.

Um eventual ponto polêmico desse caput se trataria da possibilidade de autodeclaração como startup, fazendo com que qualquer empresa, ainda que não se tratasse desse nicho empresarial, pudesse se beneficiar dessa legislação mediante uma simples afirmação própria. Todavia, o $\S 1^{\circ}$ enterra tal possibilidade, e pacificação no Brasil, o que deve ser considerado como startup.

Se trata, portanto, da definição oficial do estado sobre o que deve ser encarado como empresa startup, definição que veio na direção correta e convergindo com o que a doutrina internacional se manifestava acerca da melhor conceituação. Destacase:

$\S 1^{\circ}$ Para os fins desta Lei Complementar, considera-se startup a empresa de caráter inovador que visa a aperfeiçoar sistemas, métodos ou modelos de negócio, de produção, de serviços ou de produtos, os quais, quando já existentes, caracterizam startups de natureza incremental, ou, quando relacionados à criação de algo totalmente novo, caracterizam startups de natureza disruptiva. (Brasil, 2019, grifos nosso).

Houve a opção pelas características de inovação que pode incidir sobre o método, o modelo de negócio, produto ou serviço relacionado à criação de algo novo e disruptivo. Todo esse conglomerado de particularidades irá trazer como consequência lógica para a startup um incremento dos riscos e das incertezas sobre o seu sucesso.

Isso porque, enquanto uma nova empresa clássica irá abrir suas atividades em cima de um modelo tradicional e já consolidado, ela possuirá precedentes de sucesso pelos quais poderá se basear e ter um norte a seguir, haja vista que algum 
caminho já foi perseguido com sucesso. No caso de uma startup, a disrupção e inovação tornam o seu modelo de negócios instável, forçando-a a descobrir o caminho das pedras.

E parece que essa foi a compreensão que teve o legislador, onde através do parágrafo $2^{\circ}$ dessa norma, complementou a definição de startup, dispondo que se caracteriza dessa forma, sempre que:

$\S 2^{\circ}(\ldots)$ desenvolver suas inovações em condições de incerteza que requerem experimentos e validações constantes, inclusive mediante comercialização experimental provisória, antes de procederem à comercialização plena e à obtenção de receita. (Brasil, 2019, grifos nosso).

A incerteza quanto ao seu futuro será sempre mais presente, até que haja uma validação e consolidação em cima da sua forma de produzir, comercializar e operar a sua estrutura, proposta, serviço e/ou produto.

Dessa forma, o Inova Simples trouxe como um tratamento diferenciado para as startups a possibilidade dessas empresas utilizarem um rito sumário tanto para abrir como para fechar essas empresas. Dentre as queixas feitas por empresários brasileiros, uma delas é com relação ao tempo necessário para abrir ou fechar um CNPJ, sendo elencado como um ponto burocrático que dificulta a vida do empreendedor nesse país.

Nesse sentido, o parágrafo $3^{\circ}$ dessa lei complementar tornou simplificada e automática a abertura de CNPJ, onde através de sítio eletrônico, os titulares da empresa preencherão um formulário virtual contendo as informações solicitadas, que caso seja realizado corretamente, ao final do procedimento, será gerado automaticamente um número de cadastro específico de pessoa jurídica.

Além de tudo isto, será feita integração direta e automática desse sistema virtual de abertura de CNPJ, que é o portal Redesim - Rede Nacional para a Simplificação do Registro e da Legalização de Empresas e Negócios, com o INPI, que é o órgão oficial responsável por fazer o registro e regular a titularidade da propriedade industrial no Brasil, fazendo o registro e concessão de marcas, patentes, desenho industrial, transferência de tecnologia, entre outros.

Houve a desburocratização de série de procedimentos que demandariam possivelmente meses, atrasando o início da operação de startup, prolongando o início das atividades e dificultando a vida do empresário. Com concentração de várias etapas em uma única, e tudo isso em sítio digital, há economia de tempo e dinheiro, verdadeiro incentivo ao surgimento e criação de novas empresas no país.

No parágrafo $8^{\circ}$, há o estabelecimento de encargo para o INPI de criar um mecanismo que seja capaz de concatenar a recepção dos dados da redesim, para fazer o processamento sumário dessas informações de solicitação de marcas e patentes dessas empresas do Inova Simples. Sempre que uma startup ou empresa nascem, surgem com elas propriedades intelectuais que merecem a devida tutela jurídica, de modo que para que houvesse maior segurança jurídica, seria preciso fazer o respectivo registro formal. A unificação desses procedimentos é verdadeira iniciativa facilitadora para os empresários.

Não apenas a abertura, mas também o fechamento dessas corporações foi facilitado, onde o parágrafo $11^{\circ}$ estabelece que a baixa do CNPJ também será automática, mediante um simples procedimento de autodeclaração no portal da redesim, evitando maiores discussões e burocracias que seriam submetidos os fundadores de startups que não deram certo.

Dessa maneira, destaque-se o parágrafo $9^{\circ}$, que deixa claro a maneira como a Receita Federal brasileira deverá interpretar a capitalização de recursos de uma startup. Segundo esse trecho, não constituirá renda, e, portanto, não haverá a incidência do respectivo dever de contribuir com o imposto de renda, desde que a destinação desse recurso seja exclusiva para o custeio e desenvolvimento de projetos de startups.

Assim, houve verdadeira isenção tributária concedida para as startups receberem aporte de recursos. Isso porque, muito embora haja a capitalização de recursos, essa operação não produzirá repercussões tributárias, fazendo com o montante em sua integralidade permaneça com a startup, podendo ser direcionado para a concretização dos seus objetivos. 
Se trata de verdadeira renúncia fiscal por parte do estado brasileiro, que abre mão de recursos que ingressariam aos cofres públicos, em detrimento do incentivo feito para as startups. Deve ser reconhecida e dado o devido valor a essa legislação, na medida em que, além de desburocratizar os procedimentos de abertura e fechamento de CNPJ para startups, há também a concessão de subsídios que garantem uma margem orçamentária maior para essas empresas, na medida em que a contribuição de impostos será menor: "§ $9^{\circ}$ Os recursos capitalizados não constituirão renda e destinar-se-ão exclusivamente ao custeio do desenvolvimento de projetos de startup de que trata o $\S 1^{\circ}$ deste artigo.”

Ao receber o investimento, seja de investidores-anjo ou qualquer outra modalidade, será isento de contribuição tributária em cima desse valor, uma vez que a norma expansiva, abrindo a possibilidade para qualquer recurso capitalizado, independente da sua origem. Desde que haja regularidade na destinação dos recursos, que deverão ser voltados para a finalidade da startup, tal benefício será concedido para a companhia.

Já se destacam no mundo todo, e também no Brasil, as Healthtechs ligadas à área de saúde, das quais se destaca a ConquerX: empresa que comercializa um biosensor capaz de realizar o diagnóstico de mais de dez tipos de câncer, que através da união de nanotecnologia com inteligência artificial, esse produto é capaz de processar e cruzar milhões de dados e biomarcadores, realizando um diagnóstico num tempo $90 \%$ menor do que os métodos usuais, com um custo infinitamente menor (o custo de um exame usual chega a $\mathrm{R} \$ 9.000,00$ (nove mil reais) no BRASIL em 2018, enquanto o do ConquerX, $\mathrm{R} \$ 10,00$ (dez reias), sem precisar submeter o paciente a exames invasivos e longos, utilizando-se apenas de um exame de sangue.

As Legaltechs são startups voltadas para o setor jurídico. Destaca-se dentre as opções a companhia Sem Processo, que é uma plataforma virtual que conecta advogados de consumidores a departamentos jurídicos de empresas demandadas, onde a petição inicial de eventual litígio é inserida dentro desse sistema, e, em poucos dias, uma resposta da litigada é recebida, evitando assim a judicialização de demandas. Existem ainda as Edutechs, centradas para a área da educação, as SmartCitiestechs para o desenvolvimento de cidades, dentre outras modalidades.

Assim, percebe-se que há ausência de clareza sobre quais tributos federais seriam excluídos para as empresas que aderirem ao SISTENET, se seriam todos ou apenas parte, uma vez que a norma fala abertamente em excluir "impostos federais". Se considerados em sua totalidade, o benefício poderia chegar a 15\% do faturamento dessas empresas, quando considerados PIS, COFINS, contribuições previdenciárias e sociais etc.

Dessa forma, conclui-se que merece reformulação o texto original, uma vez que traz uma conceituação ruim, abrindo margem para uma interpretação ambígua, que pode proporcionar insegurança jurídica, quando da sua execução, excluindo diversas empresas que poderiam ser consideradas startups e aderirem ao sistema que traz benefícios e incentivos, desenvolvendo de maneira indesejada esse ecossistema. Além do mais, o valor da renda anual considerado também é muito pequeno, levando, consequentemente, a uma baixa possibilidade de adesão ao sistema.

Não existe até o presente momento termo legal brasileiro que conceitue, restando à (pouca) doutrina existente essa função. Logo, para a presente dissertação, adota-se as seguintes características para conceituar uma empresa como startup:

a) perfil inovador ${ }^{2}$ e disruptivo: Trata-se do grau máximo dentro das opções de inovação, posto que se trata daquela que possui capacidade de romper o status quo, a dinâmica e práticas estabelecidas no mercado em que irá concorrer, onde se cria algo que não existia até então ou se reformula a maneira de fazer negócio, desestabilizando o establishment. "Inovação disruptiva" (Christensen \& Bower, 1995), segundo Clayton Christense e Joseph Bower, seria a entrada rápida e arrebatadora sobre um sistema já estável de um mercado. Tomemos como exemplo a Airbnb: inovou no mercado hoteleiro que já se encontrava há décadas estabilizado, que tinha um modelo de negócios consolidado e definido, até que essa startup se instalou, e provocou uma disrupção no sistema. Essa empresa, através de tecnologia une um potencial consumidor a um proprietário de imóvel disponível interessado em hospedar alguém, em troca de um valor bem abaixo do praticado pelos hotéis. Assim, barateou-se consideravelmente o serviço, sobretudo porque os custos nessa operação

${ }^{2}$ Conceito muito explorado por Eric Ries (2012). 
são bem menores quando comparados com a hotelaria comum, haja vista que se utiliza basicamente de uma plataforma digital. Houve também uma simplificação do serviço, tornando-o mais acessível, pois exige-se documentação menor para se hospedar. Segundo dados de uma pesquisa realizada em 2017 pela Fundação Instituto de Pesquisas Econômica (FIPE), no Brasil, o Airbnb já movimenta três vezes mais a economia que os hotéis (Salomão, 2017);

b) produto/ideia/serviço é escalável e repetível: Essas características sinalizam que o crescimento de uma startup ocorre, comumente, de maneira exponencial, uma vez que o seu produto/serviço é capaz de ser reproduzido e comercializado em qualquer outro mercado e em qualquer local do mundo. Por dispor de uma manutenção de custos baixa, a proporção de crescimento dos lucros é inversamente proporcional aos custos, vez que se utiliza de tecnologia, inteligência artificial, entre outros recursos, para seu desenvolvimento (Feigelson, Fontenele, \& Fonseca, 2018, p. 25) e manutenção. Desta feita, é possível aumentar a demanda sem crescer tanto as despesas, facilitando a sua replicação e expansão para outros mercados. Podemos citar como exemplo o caso da Uber: com origem nos Estados Unidos, essa companhia logo se tornou multinacional. Além de que a demanda por mais corridas pode não implicar em nenhum aumento significativo de despesas para a empresa. Quando comparada com uma empresa de táxi, onde diante de um aumento de demanda, seria necessário para o proprietário adquirir novos automóveis ou alugá-los, contratar novos motoristas, aumentando a sua folha de pessoal e encargos, pagar gasolina e os respectivos impostos, além de uma série de outros gastos que haveriam diretamente para aquela empresa;

c) modelo de negócios desconhecido: Ainda sobre a Uber, muito embora o serviço de transporte de passageiros já existisse quando do lançamento dessa empresa, porém, a maneira como essa companhia se propôs a prestar o serviço foi completamente inovadora, com um planner que era totalmente desconhecido, pois não havia algo consolidado que fosse similar a sua proposta e que poderia ser aproveitado como base. Quando se toma como base uma padaria, o modelo de negócios desse ramo é pré-existente, conhecido e consolidado: isso implica em dizer que os potenciais consumidores são potencialmente conhecidos; a maneira como atraí-los igualmente, o produto oferecido já está bem desenhado e base para precificá-lo bem definida. Sobre a Uber, quando de sua criação, tudo isso era bastante incerto e desprovido de parâmetros, vez que não existia algo que unisse, através da tecnologia, um passageiro interessado no transporte a um motorista disponível para ir a qualquer destino, partindo de qualquer local e a qualquer momento. Não se sabia quem seriam os potenciais consumidores, como encontrá-los, o valor médio a ser cobrado pelas corridas etc.;

d) estágio inicial ${ }^{3}$ : Segundo Bruno Feigelson, Erik Fontenele e Victor Fonseca, essa característica comum às startups se reflete no fato de que por apresentar inovação, essas empresas carecerão de desenvolvimento e amadurecimento, onde serão marcadas pela carência de processos internos e protocolos de organização que serão desenvolvidos com o tempo (Feigelson, Fontenele \& Fonseca, 2018, p. 25). Essa é uma das características mais importantes para o nosso objeto de estudo, uma vez que ela é o elemento que fortalece a relevância que um investidor-anjo passa a ter para startups. Muitas vezes, os fundadores dessas companhias possuem apenas uma ideia de produto ou serviço que tem um grande potencial disruptivo, escalável e lucrativo, com capacidade para se tornar uma gigantesca empresa no futuro. Porém, são na maioria das vezes jovens ou pessoas que não têm qualquer experiência empresarial, sobre gestão e marketing comercial, carecendo completamente de ajuda, não apenas no quesito financeiro, mas na administração e gestão do negócio;

e) riscos e incertezas: São dois elementos facilmente identificáveis para uma startup. Conforme já abordado, esse tipo de empresa muitas vezes nasce de uma ideia, uma oportunidade descoberta, uma tendência que existe no mercado ou é a solução encontrada para um problema. Acontece que existe uma série de passos e grandes obstáculos a serem vencidos, que vão desde a idealização do produto ou serviço, até a sua realização, materialização e consolidação desta potencial inovação disruptiva no mercado. Será preciso encontrar o plano de negócios, que será pioneiro, formando uma equipe que tenha capacidade para desenvolver a ideia. Criar, formatar, desenhar e consolidar de maneira muito clara o produto/serviço. Encontrar financiadores que possam aportar capital que tornará tudo isso realidade, viabilizando a circulação do produto/serviço no mercado, para, ao final, se tudo der certo, haver a consolidação da inovação perante o mercado consumidor. Confirmando essa tese, a Fundação Dom Cabral, através de análise recente (Arruda el al., 2012), demonstrou que $50 \%$ das startups fecham suas portas nos quatro primeiros anos de fundação, o que ratifica o caráter frágil dessas empresas. Dessa forma, quando houver a consolidação do produto ou serviço oferecido pela startup, ela deixará de ser assim considerada, haja vista que não haverá tantos riscos e incertezas sobre o seu negócio, possibilitando, inclusive, a sua replicação através de concorrentes. Foi exatamente isso que ocorreu com a Uber. Após a sua consolidação no mercado, houve a criação de diversos concorrentes, dentre os quais podemos citar o primeiro unicórnio ${ }^{4}$ brasileiro: a 99. (Brigatto, 2018).

Feitas essas considerações, cabe afirmar que startup é uma organização vocacionada a ostentar essa qualidade de maneira temporária, posto que para ser assim definida, ela precisa navegar em um modelo de negócio ainda não consolidado no

3 Destaque-se essa característica, pois sua relevância será explorada mais a frente, linkando com a possível contribuição de um investidoranjo.

${ }^{4}$ Dentro do ecossistema, as startups que um dia foram muito pequenas, e que cresceram a ponto de alcançar um valuation (avaliação de preço no mercado) de $\$ 1.000 .000 .000$ (um bilhão de dólares) são assim chamadas. 
mercado e repleto de incertezas. Se ela ultrapassar essa barreira e consolidar o seu negócio, isso implica dizer que ela deu certo. Houve aceitação dos seus produtos, ela começou a faturar, haverá um crescimento exponencial e escalável.

Desse modo, empresas que se iniciaram como startups, a exemplo de Uber, Airbnb, ZipCar, conceitualmente, não podem mais ser classificadas dessa forma, uma vez que o seu modelo de negócios foi consolidado, tanto o é que já possuem até aplicativos e empresas concorrentes, reproduzindo o business plan estabilizado pela primeira startup.

Reforce-se ainda que não é o fato de a startup utilizar ou ser baseada em tecnologia que irá classificá-la dessa maneira. Seria esse um conceito muito pequeno para conceituar esse ramo empresarial dessa maneira, haja vista que é possível qualquer negócio, seja ele inovador ou não, utilizar-se excessivamente de tecnologia. Além do mais, é uma tendência, praticamente, obrigatória para as companhias, modernizarem-se e explorar ao máximo os avanços ofertados pela ciência.

Como por exemplo, já existem casos de farmácias ou supermercados sem funcionários, cujo modelo de negócio que é amplamente solidificado, em que robôs substituíram completamente o trabalho humano. Sob a ótica do conceito adotado por esse trabalho, essa drogaria não estaria se transformando em uma startup, mas apenas passando por um processo de modernização, que em nada reformou o seu business plan.

Com o processo de avanço e surgimento de novas tecnologias, é inevitável que startups, que são companhias que surgem com uma proposta de inovação, invariavelmente, em qualquer momento de sua operação, irão se utilizar, até mesmo com uma dependência maior do que outras empresas tradicionais, de avanços tecnológicos, a exemplo de plataformas virtuais, inteligência artificial, realidade aumentada, internet das coisas, mas seria apenas um meio para se alcançar uma finalidade (produto/serviço) ofertado pela empresa.

São, portanto, companhias em busca de um negócio inovador, disruptivo, escalável, lucrativo e incerto, que no início caracteriza flexibilidade de ideias e suposições, baseadas fortemente na tecnologia, e que possui um modelo de negócios pioneiro. Não é, portanto, apenas uma empresa de porte pequeno, que esteja iniciando suas atividades ou que se utilize bastante de tecnologia em seu negócio, como o senso comum acredita.

Destaque-se, ainda, que startup é uma empresa como outra qualquer. No Brasil, inexiste qualquer diferenciação ou privilégios concedidos a essa espécie empresarial, aplicando-se a ela todos os ditames legais das mais diversas searas jurídicas, desde a trabalhista, tributária, cível, penal e empresarial.

Dessa maneira, por se tratar de um ramo empresarial novo, recheado por incertezas e riscos, é de extrema importância avaliar no caso concreto quais as opções fornecidas pela sistemática brasileira que melhor se encaixam no modelo de negócios que será desenvolvido, para que haja proteção aos atores envolvidos no processo de criação e desenvolvimento dessas empresas, a exemplo dos fundadores e investidores, garantindo o máximo de segurança jurídica.

\section{Considerações Finais}

Percebe-se, mediante considerações abordadas durante o texto, que as startups já desempenham e que podem vir a contribuir no futuro é tamanha, isso porque se tratam de verdadeiros vetores do avançar da tecnologia. No entanto, inexiste um tratamento específico voltado as startups, sendo aplicada toda e qualquer texto normativo das diversas searas jurídicas, desde a trabalhista, tributária, cível, penal e empresarial.

Além disso, salienta-se que é necessário encontrar um ponto de equilíbrio na legislação brasileira em vigor que traga segurança jurídica e que melhor se encaixe no modelo societário para os financiadores-anjo, levando em consideração a realidade dos investidos que não podem de maneira generalizada assumir com exclusividade as responsabilidades.

Assim, startup embora seja um tipo de empresa, ela carrega na sua essência incertezas e riscos a mais, os quais podem ser minimizados por essa modalidade de investidores, os angels, fazendo com que eles sejam muitas vezes peças de fundamental importância para o desenvolvimento de startups, empresas com grande potencial de crescimento e, portanto, com grande 
potencial de contribuição para o nosso país, seja porque vão gerar renda, empregos, arrecadação para o Estado, movimentação da economia, entre outros.

Dessa maneira, como forma de assegurar, de forma eficaz, o pleno desenvolvimento das startups, acreditamos que investigações como esta devem ser prosseguidas. Sendo assim, como sugestão para continuidade de discussões nesse sentido, analisar, à luz do Direito Empresarial, de que modo as inovações normativas tratam acerca das startups, contribuirá para o fortalecimento e planejamento de estratégias de atenção a este segmento assim como desenhar e formular novos e mais efetivos caminhos como forma de assegurar uma segurança jurídica no cerne negocial.

\section{Referências}

Arruda, C., et al. (2012). Causas da Mortalidade de Startups Brasileiras. O que fazer para aumentar as chances de sobrevivência no mercado. https://www.fdc.org.br/blogespacodialogo/Documents/2014/causas_mortalidade_startup s_brasileiras.pdf

Azevedo, J. C. R. (2016). Inovação, startup e o direito. In: Nybo, E. F., Júdice, L. P. (org.). Direito das Startups. São Paulo: Juruá.

Bauman, Z. (2014). Modernidade Líquida. Rio de Janeiro: Zahar, 2001. In: GRINOVER, Ada Pellegrini et al. (org.). Processo Coletivo: do surgimento à atualidade: Revista dos Tribunais.

Benvenutti, M. (2018). Audaz: as 5 competências para construir carreiras e negócios inabaláveis nos dias de hoje: Editora Gente.

Blank, S., \& Dorf, B. (2012). The Startup Owner's Manual: The Step-by-Step Guide for building a great company: K\&S Ranch, Inc.

Brasil. (2013). Parecer no Projeto de lei 6.625/2013, da Câmara dos http://www.camara.gov.br/proposicoesWeb/prop_mostrarintegra;jsessionid=5FCCDEC85E6F8F13D2133A3CE0AE444F.proposicoesWebExterno2?codteor= $1321274 \&$ filename=Parecer-CCTCI-15-04-2015

Brasil. (2019). Lei Complementar $n^{\circ} \quad 167, \quad$ de 24 de http://www.planalto.gov.br/ccivil_03/leis/lcp/lcp167.htm\#: :text=Disp\%C3\%B5e\%20sobre\%20a\%20Empresa\%20Simples,e\%20instituir\%20o\%20Inova\%20 Simples.

Brigatto, G. Didi compra a 99, que vale US\$ 1 bi. <https://www.valor.com.br/empresas/5243261/didi-compra-99-que-vale-us-1-bi>.

Chase, R. (2015). Economia compartilhada: como as pessoas e as plataformas estão inventando a economia colaborativa e reinventando o capitalismo. Tradução de Cristina Yamagami: HSM do Brasil.

Christensen, C., \& Bower, J. (1995). Disruptive Tecnologies: Catching the Wave. Havard Business Review, 73(1), January-February.

Dagnino, G. B. (2017). Investidores anjo brasileiros desembolsam $R \quad 984 \quad$ milhões em startups em 2017. https://www.dci.com.br/empreendedorismo/investidores-anjo-brasileiros-desembolsam-r-984-milh-es-em-startups-em-2017-1.734260

Diamandis, P. (2016). The 6 Ds of Tech Disruption: A Guide to the Digital Economy. https://singularityhub.com/2016/11/22/the-6-ds-of-tech-disruption-aguide-to-the-digital-economy/

Empreendedorismo. (2018). In: DICIONÁRIO do Aurélio. https://dicionariodoaurelio.com/empreendedorismo

Estadão. Em 1998 telefonia era cara, e tinha fila de espera. https://link.estadao.com.br/noticias/cultura-digital,em-1998-telefonia-fixa-era-cara-e-tinha-fila-deespera,70002420042

Feigelson, B., Fontenele, E., \& Fonseca, V. C. (2018). Direito das Startups: Saraiva Educação.

Forbes. (2014). In One Chart, Here's Why Facebook Is Blowing \$19 Billion On WhatsApp. https://www.forbes.com/sites/roberthof/2014/02/19/in-one-chartheres-why-facebook-is-blowing-19-billion-on-whatsapp/.

Guilhermino, E. B. (2018). A tutela das multititularidades: repensando os limites do direito de propriedade: Lumen Juris.

GODIN, Seth. The Bootstrapper Bible. http://changethis.com/8.BootstrappersBible.

Itália. (2012). Lei 221, de 2012. www.rio.jrc.ec.europa.eu/en/library/law-17-december-2012-n221-innovative-start-ups

Ramirez, V. B. (2016). The 6 Ds of Tech Disruption: A Guide to the Digital Economyhttps://singularityhub.com/2016/11/22/the-6-ds-of-tech-disruption-a-guideto-the-digital-economy/

Ries, E. (2012). A startup enxuta - como os empreendedores atuais utilizam a inovação para criar empresas extremamente bem-sucedidas. São Paulo: Lua de Papel.

Salomão, K. (2017). Airbnb movimenta 3 vezes mais a economia no Brasil que hotéis. FIPE. https://exame.abril.com.br/negocios/airbnb-movimenta-3-vezesmais-a-economia-no-brasil-que-hoteis/

Schwab, K. (2016). A quarta revolução industrial. Tradução de Daniel Moreira Miranda: Edipro. 